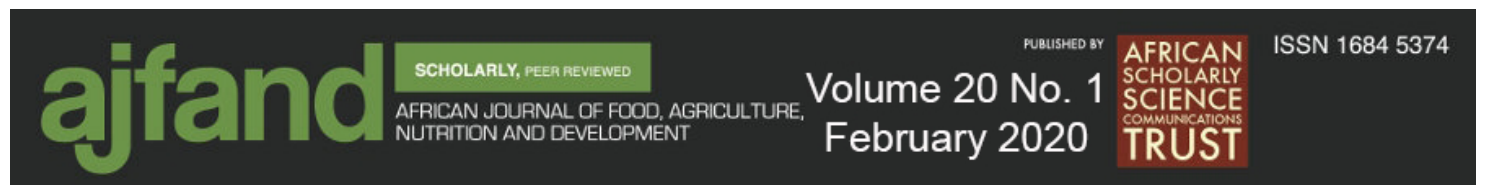

Afr. J. Food Agric. Nutr. Dev. 2020; 20(1): 15235-15251 ～DOI: 10.18697/ajfand.89.17520

\title{
HIGH VARIABILITY OF IODINE IN IODIZED SALT AND URINE FROM RURAL HOUSEHOLDS IN SIDAMA ZONE, SOUTHERN ETHIOPIA: \\ A CROSS-SECTIONAL STUDY
}

Tafere $\mathbf{G}^{1 *}$ and BJ Stoecker ${ }^{2}$

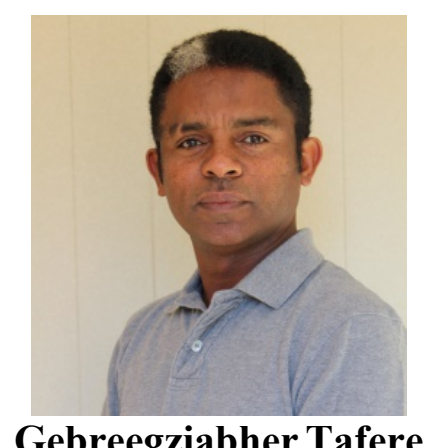

Gebreegziabher Tafere

*Corresponding author email: tafere.bl@gmail.com

${ }^{1}$ Central Washington University, Dept. of Health Sciences, 400 E University Way, Ellensburg, WA 98926, USA

${ }^{2}$ Oklahoma State University, Nutritional Sciences, 421 Human Sciences, Stillwater, OK 74078, USA 


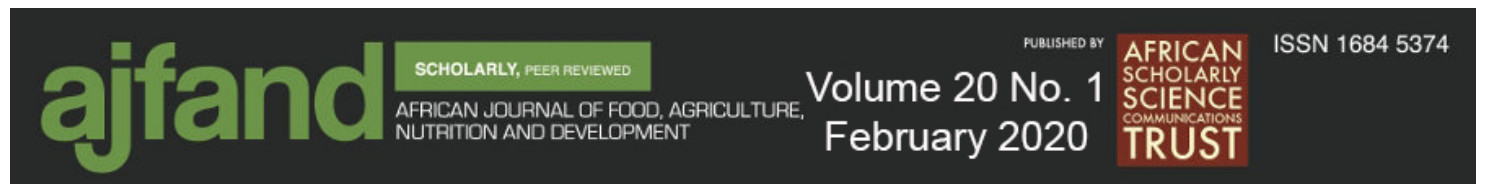

\begin{abstract}
Iodine is essential for the synthesis of thyroid hormones which regulate the metabolic processes of most cells and play important roles in human growth and development. Iodine deficiency has long been one of the most common nutritional problems in the world. Ethiopia, particularly the study population (Sidama) has a history of severe iodine deficiency. The purpose of the study was to assess urinary iodine concentration, level of goiter in mothers and school-age children and household salt iodine concentration in households 10 months after launch of the national salt iodization program. A crosssectional study was conducted on a randomly selected sample of women and schoolchildren. Goiter was assessed by palpation. Concentrations of iodine in salt, urine and water were analyzed by inductively coupled plasma mass spectrometry (ICP-MS). The study included 193 mothers and 76 children. The median (IQR) urinary iodine concentration (UIC) was $143(84,202) \mu \mathrm{g} / \mathrm{L}$ in the mothers and $187(102,278) \mu \mathrm{g} / \mathrm{L}$ in the children. Mothers' UIC ranged from 17 to $767.2 \mu \mathrm{g} / \mathrm{L}$ and children's UIC ranged from 19 to $739 \mu \mathrm{g} / \mathrm{L}$. Goiter prevalence was high in both mothers $(76 \%)$ and children (79\%). The median household salt iodine concentration (SIC) was 8.1 $(4.3,13.4) \mathrm{ppm}$ $(\mathrm{mg} / \mathrm{kg})$ with a range of 0 to $42 \mathrm{ppm}$. None of the water samples contained iodine above the detection limit of $1 \mu \mathrm{g} / \mathrm{L}$. Despite the launch of the salt iodization program in Ethiopia, 94\% of the study participants were not aware that they used iodized salt and $88 \%$ did not know the benefits of iodized salt. The major source of iodine for this population was iodized salt; however, the salt at household level contained minimal but variable amounts of iodine. Low concentration of iodine in salt may be further compounded by storage, handling and cooking techniques. The high variability of salt iodine concentration (SIC) was also reflected in the UIC of the mothers and children.
\end{abstract}

Key words: Iodized salt, urinary iodine, goiter, children, mothers, southern Ethiopia 


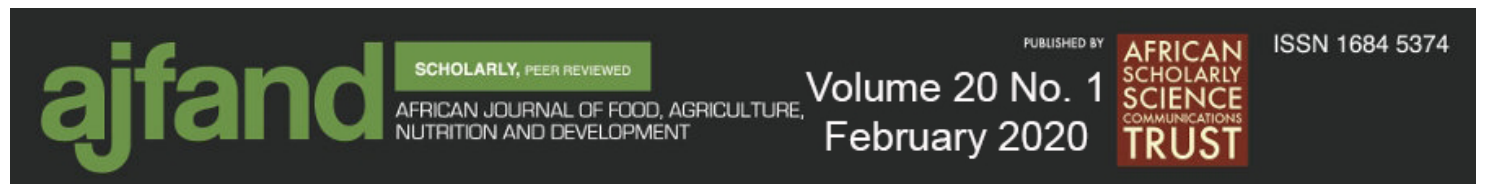

\section{INTRODUCTION}

Iodine is a chemical element found in trace amounts in the human body and is primarily obtained through the diet [1]. Iodine is essential for the synthesis of thyroid hormones which regulate the metabolic processes of most cells and play important roles in human growth and development [2].

Iodine deficiency is one of the most common nutritional problems of the world. Globally, it was estimated in 2009 that 2 billion people, most of them in low income countries, suffered inadequate intakes of iodine [3]. Due to its multiple effects on human health, iodine deficiency is referred to as iodine deficiency disorders (IDDs) [4]. Enormous progress towards eliminating iodine deficiency has been made however, the deficiency continues to reappear even in medium and high income countries [5].

In a survey conducted in Ethiopia in 2005, goiter prevalence was 35.8\% among 15 to 49 years old women and $40 \%$ in school age children. In the southern region of the country, of 1702 women examined for goiter, $43.2 \%$ had palpable and $17.7 \%$ had visible goiter, which is a total goiter prevalence of $60.9 \%$. In school children in the same region, the prevalence of goiter was $56.2 \%$. These data show that Ethiopia, particularly the southern region, was severely affected by iodine deficiency $[6,7]$.

Iodine is widely distributed in the environment as iodide. Iodine found in the soil can be washed away by leaching, flooding and erosion, which leaves the soil and drinking water depleted of iodine. Plants grown in this soil will be low in iodine content and hence animals and humans that rely on these plants will most likely become iodine deficient [8]. For people who reside in iodine-deficient areas, the best ways to alleviate iodine deficiency are using iodized salt and diversifying local food with foods from iodinesufficient areas. Iodine containing fertilizers, livestock feed, and compounds used in irrigation and milk processing can increase iodine content in foods including dairy products [3].

A review of reports from 30 low income countries showed that urinary iodine concentration (UIC) was significantly correlated with household iodized salt availability [9]. In a prospective study of women 18 to 65 years old in Denmark, a lower median thyroid volume was observed 4 years after a mandatory salt iodization (13 ppm iodine) program. Further, a large relative decline of thyroid volume was observed in the younger females from places where iodine deficiency had been more serious compared to mild [10]. A national survey on iodine deficiency was conducted in Tanzania after twelve years of a salt iodization program. The iodine status of school children, aged 6 to 18 years, was assessed by goiter level $(\mathrm{n}=140,358)$ and UIC $(\mathrm{n}=4523)$. Total goiter significantly decreased from $61 \%$ in the 1980 s to $12.3 \%$ in 2004 and the median UIC was found to be $204 \mu \mathrm{g} / \mathrm{L}$ [11].

In Ethiopia, the salt iodization program was launched early in 2012. Data were collected in early 2013 and approximately a year later, the Ethiopian Public Health Institute reported $95.2 \%$ national iodized salt coverage (above $0 \mathrm{ppm}$ ) with $42.7 \%$ of the households having salt with iodine greater than $15 \mathrm{ppm}$. Households with salt within the 


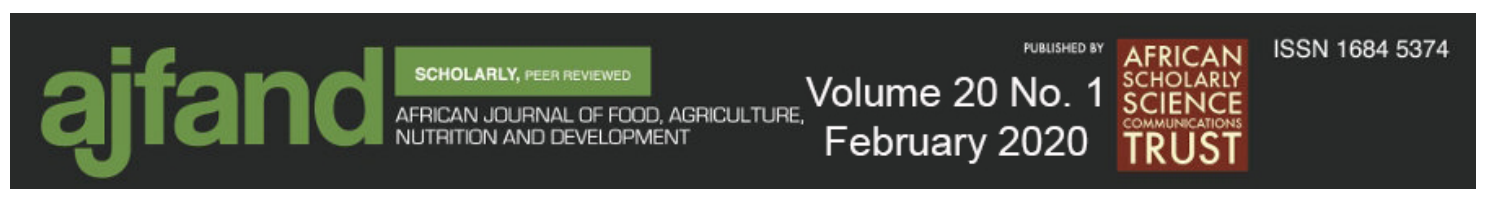

national standard (20 to $40 \mathrm{ppm}$ ) were $23.2 \%$ [12]. However, to the best of our knowledge, no study has reported the impact of the salt iodization program on urinary iodine or goiter in the southern part of the country following the launch of the salt iodization program. Further, local knowledge about the health benefits of iodine subsequent to initiation of the national program had not been assessed.

The purpose of the present study was to assess urinary iodine concentration, goiter in mothers and school-age children and household salt iodine concentration in a sample of households 10 months after launch of the national salt iodization program. Moreover, knowledge of mothers about IDDs as well as their practices and utilization of iodized salt were assessed.

\section{MATERIALS AND METHODS}

\section{Study area and design}

The study was conducted in Sidama zone, southern Ethiopia, where iodine deficiency was severe prior to the national salt iodization program [13-15]. The study area has a variety of climate conditions and its elevation ranges from $1678 \mathrm{~m}$ to $1809 \mathrm{~m}$ above sea level. The major staple foods are corn and enset (Enset ventricosum) [16].

Before the study began, ethical approval was obtained from Oklahoma State University, USA, Hawassa University, Ethiopia, and Ministry of Science and Technology, Ethiopia. The study participants were recruited from eight kebeles (the smallest administrative unit) from a randomly selected sample of households which included women $(n=193)$ and their school age children $(n=76)$. Households were selected using random numbers from lists of households available in the kebele health center. Any woman or school age child available in the house during the time of data collection was invited to participate. Study participants were given a detailed explanation of the objectives of the research, and consent forms were read to the women. Women signed for themselves and their children before data collection was started. Because $90 \%$ of dietary iodine is excreted in the urine, UIC is a commonly used indicator for iodine status of a community [17]. Each participant collected a urine sample in a plastic cup; samples were transferred to tightly sealed vials for subsequent analyses. Water samples from eight communal water tap points and from nearby Lake Awassa were collected for iodine analysis. A $10 \mathrm{~g}$ salt sample was collected from each household.

Each mother's knowledge, attitudes and practices about iodized salt, iodine deficiency, goiter and other related factors were assessed using open-ended questions, which were re-coded for analysis. Socio-demographic data were collected by interview using structured questionnaires.

\section{Laboratory analysis and goiter assessment}

Urinary and drinking water iodine concentrations were analyzed by inductively coupled plasma mass spectrometry (ICP-MS Elan 9000, Perkin Elmer, Norwalk, CT). Salt iodine concentration (SIC) was analyzed with a digital electronic iodine checker (WYD, UNICEF) and validated using inductively-coupled-plasma mass spectrometry. Measured SIC using the two methods demonstrated a good correlation $(r=0.745, p<0.001)$. 


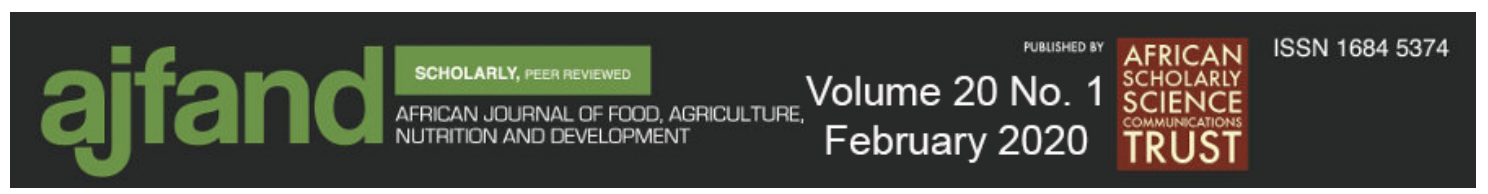

Goiter of mothers and children was determined by palpation based on the following grades: grade 0, no palpable or visible goiter; grade 1, palpable goiter not visible with neck in normal position; and grade 2, visible goiter with neck in its normal position [17]. Goiter was assessed by an experienced health officer.

\section{Statistical analysis}

Data were analyzed using SPSS statistics for Windows v. 20.0 (Armonk, NY: IBM Corp.). Frequency, percentage and median (IQR) were used to present the data. Pearson's correlation coefficients and the Chi square test were used to test for association. To test whether or not the means of three or more groups were equal, we used Tukey's honestly significant test (Tukey's HSD) and for two groups we used independent-sample t tests.

\section{RESULTS and DISCUSSION}

\section{Descriptive results}

Demographic and socio-economic characteristics of study participants are presented in Table 1. The mean (SD) age of the mothers was 25.6 (8.1) and of the children was 9.6 (4.4) years. The mean household size was 5.7 (2.1) and mean number of children was 3.2 (1.8). Among the children who participated in this study, $60 \%$ were males. Of the respondents, $55 \%$ had some formal education.

The median UIC of mothers was $143 \mu \mathrm{g} / \mathrm{L}$ and of the children was $187 \mu \mathrm{g} / \mathrm{L}$, which is above the cutoff $(100 \mu \mathrm{g} / \mathrm{L})$ for defining an adequate iodine area [17] (Table 2). Only one mother and one child had UIC below $20 \mu \mathrm{g} / \mathrm{L}$. Overall, based on UIC, $67.5 \%$ of the mothers and $77 \%$ of the children had adequate, more than adequate or excessive iodine intakes (Figure 1).

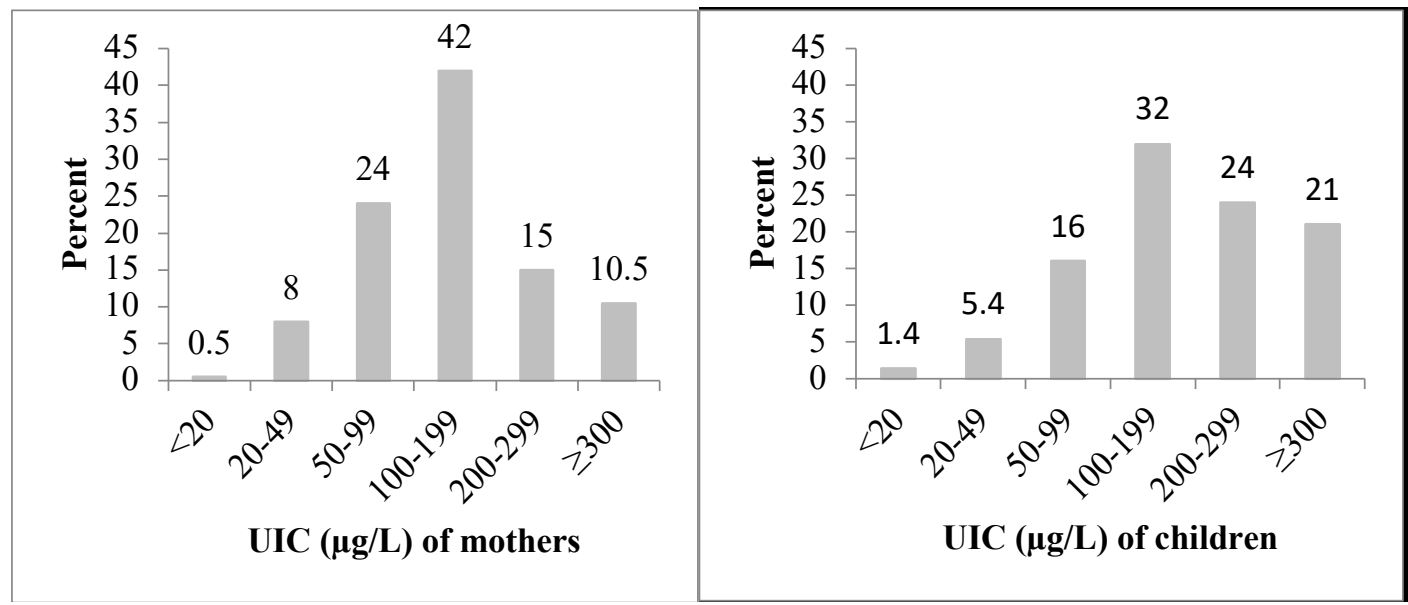

Figure 1: Distribution of urinary iodine concentrations (UIC) in a sample of mothers and children from Sidama zone, 10 months after Ethiopia's national salt iodization program was initiated

Although children had less "visible goiter" than women, goiter prevalence was high in both mothers and children. Most (76\%) of the women and $79 \%$ of the children had either 


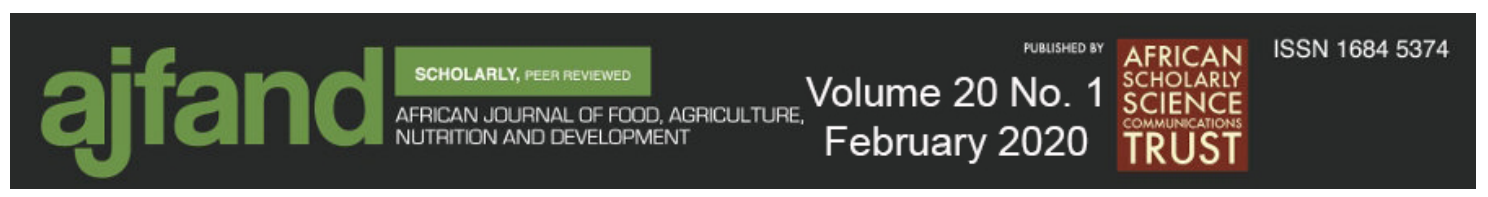

palpable or visible goiter. This prevalence of goiter was far above what would be defined as a public health problem [17] (Table 2). Mean UIC was not significantly different based on goiter in either mothers or children or between male and female children (Table 3 ). However, older mothers had significantly higher UIC compared to younger ones $[\mathrm{F}(3$, $186)=4.17, \mathrm{p}=0.007]$. Tukey's Post Hoc test showed women age 29 years and above had significantly higher urinary iodine concentration than women age 17 to 20 years old $(p=0.003)$. Children's age, was associated with level of goiter $\left(X^{2}=13.3, p=0.01\right)$ but not with UIC, and there were not significant differences in goiter by sex in children (Table 3).

\section{Salt iodine concentration}

A markedly high variation was observed in SIC. Nearly $79 \%$ of the salt samples were below the minimum (15 ppm) for adequately iodized salt (Table 2). Only $21 \%$ of the salt samples were within the recommended $15-40 \mathrm{ppm}$. One salt sample that measured 162 ppm was considered an outlier and excluded from analyses. Otherwise, SIC ranged between $0 \mathrm{ppm}$ to $42 \mathrm{ppm}$. Water iodine concentration was analyzed from eight communal tap water points and from the lake but all water samples were below the detection limit of $1 \mu \mathrm{g} / \mathrm{L}(1 \mathrm{ppb})$.

\section{Mother's awareness of salt iodization and causes of goiter}

Nearly $94 \%$ of women interviewed 10 months after the launch of salt iodization in Ethiopia did not know whether or not the salt they were using was iodized (Table 4). Except one woman, all of the women thought the salt they were buying from the market for cooking was rock (non-iodized) salt and only 24 women (12\%) knew the benefits of iodized salt. Among those, 23 women said iodized salt prevents goiter. Of the 39 women $(20 \%)$ who claimed to know the causes of goiter, only ten related goiter to lack of iodine in salt or to iodine itself.

As indicated in Table 5, most women added salt to food near the end of cooking, but $38 \%$ said they cooked the salt together with the food. Most women stored their salt in an empty plastic water bottle.

\section{Urinary Iodine Concentration (UIC) and Goiter}

The most efficient way to alleviate iodine deficiency disorders is to implement universal salt iodization [3]. Compared to previous studies from the region [13-15], present study showed marked improvement in urinary iodine and salt iodine concentrations following the launch of salt iodization in 2012 in Ethiopia. However, prevalence of goiter remained high in mothers $(76 \%)$ and in children $(79 \%)$. Guidance from WHO/UNICEF/ICCIDD suggests that goiter is likely to take some time to reverse [17]. Urinary iodine concentration (UIC) and level of goiter may not correlate as a program is introduced because UIC reflects recent iodine intake and goiter is a result of long-term iodine deprivation. In a cross-sectional study in Guinea-Bissau in school age children, rate of goiter was high $(73.5 \%)$ despite median UIC of $110 \mu \mathrm{g} / \mathrm{L}$ [18]. Similarly, in a longitudinal continuous study in Chinese population iodized salt was not associated with rate of goiter [19]. Knowledge of importance of iodine was low and needs effective intervention. 


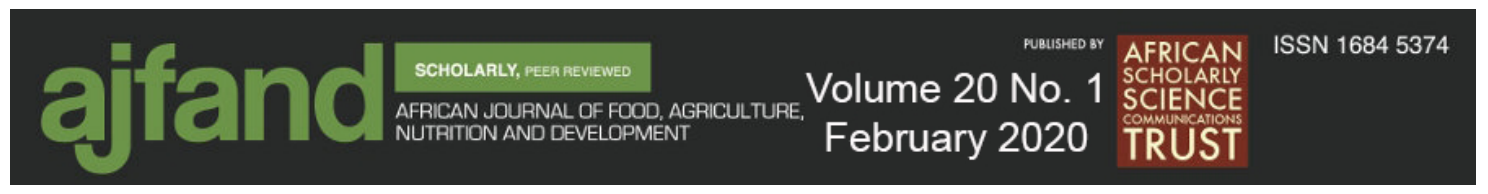

\section{Variability of urinary iodine concentration (UIC) and salt iodine concentration (SIC)}

Compared to previous studies the pattern of UIC distribution in both mothers and children is shifting towards iodine adequacy. In consecutive years from 2007 to 2010 in similar study areas in Sidama, the proportion of study participants with UIC below 100 $\mu \mathrm{g} / \mathrm{L}$ (an indicator of iodine inadequacy) was nearly 100\%. In 2007, 99\% of the schoolage children involved in the study had UIC below $20 \mu \mathrm{g} / \mathrm{L}$ [13]. In 2009, 89\% of the pregnant women had UIC below $50 \mu \mathrm{g} / \mathrm{L}$ with $60 \%$ below $20 \mu \mathrm{g} / \mathrm{L}$ [14]. Similarly, in 2010 , the proportion of women with UIC below $100 \mu \mathrm{g} / \mathrm{L}$ was $96 \%$ [15]. In the present study the proportion of mothers and children with UIC below $20 \mu \mathrm{g} / \mathrm{L}$ was almost zero. Most of the mothers (67.5\%) and children (77\%) had UIC above $100 \mu \mathrm{g} / \mathrm{L}$. However, mothers' UIC ranged from 17 to $767.2 \mu \mathrm{g} / \mathrm{L}$ and children's UIC ranged from 19 to 739 $\mu \mathrm{g} / \mathrm{L}$. This high variability in UIC could suggest potential risk for iodine-induced hyperthyroidism [20] and emphasizes the need for continuous monitoring of Ethiopia's relatively new salt iodization program.

Other than salt, the study population had poor dietary sources of iodine [15]. The iodine concentration of their drinking water was also below the detection limit of ICP-MS $(1 \mathrm{ppb})$. If local water supplies are extremely low in iodine, food grown locally also is expected to have low iodine concentrations [21]. Hence, the high variability in UIC could be explained from the high variability observed in $\operatorname{SIC}\left(X^{2}=4.43, p=0.034\right)$. Salt iodine concentration ranged from $0 \mathrm{ppm}$ to $42 \mathrm{ppm}$ with one outlier of $162 \mathrm{ppm}$. The variability in SIC is a great concern because it is highly likely that one can get salt with little iodine one day and excessively iodized salt another day. Women typically buy small amounts of salt to use for one to three days. The ultimate goal of a universal salt iodization program is to alleviate iodine deficiency but if not closely monitored, both inadequate and excessive iodine intake could be a problem [5]. According to a national report, some salt in Ethiopia was being iodized manually using knapsack sprayers and small scale iodization machines, which make it difficult to produce homogeneously iodized salt [12]. Also, iodine lost from salt by inappropriate storage [17] may contribute to the high variability in SIC. The percentage of households with adequately iodized salt ( $\geq 15 \mathrm{ppm}$ ) in other parts of the country ranged from $8 \%$ to $33 \%$ [22-24].

Although consumer awareness is necessary for a quick improvement and demand for a better product, it could be too early to comment on the Ethiopian salt iodization program. In Saudi Arabia, 20 years after a universal salt iodization program was implemented, SIC showed variation from 0 to $112 \mathrm{ppm}$ [25]. Despite a mandatory salt iodization program in Cambodia, a drastic decrease in the iodine content of salt was observed from $22 \mathrm{ppm}$ in 2011 to $0 \mathrm{ppm}$ in 2014. Presumably this drop in salt iodine content was due to infiltration of non-iodized salt from the production site to the market and/or due to inappropriate packaging of iodized salt [26]. Long-term experience from different countries has shown that salt iodization programs can only be effective and sustainable with strong monitoring strategies and commitment from government, donors, producers, distributors and consumers [27]. 


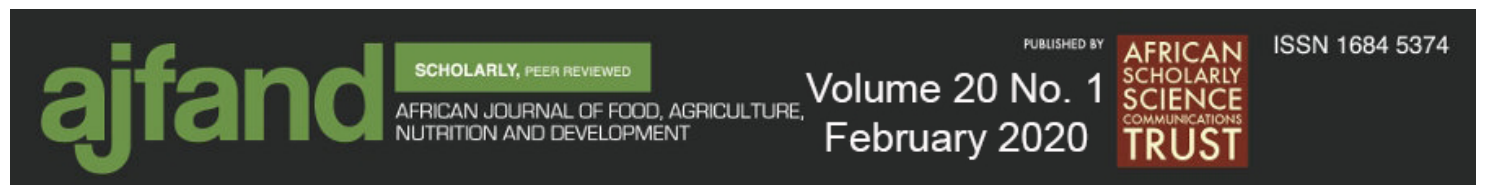

\section{Utilization of iodized salt}

Maintaining the sustainability of a salt iodization program requires its own multidimensional commitment, and retaining the iodine in the salt in turn requires careful storage and handling in the market and the household as well as proper utilization methods. Iodine is a volatile trace element and hence it can easily be lost from improper storage, handling and cooking processes. The WHO/UNICEF/ICCIDD manual suggests that $20 \%$ of iodine from salt will be lost between production and the household, and another $20 \%$ will be lost during cooking [17]. Even greater losses were found in a study in Wukro, Northern Ethiopia that reported that $57 \%$ of the salt iodine available at the production level was lost by the time it reached the household [28].

The stability of iodine in salt can be affected by moisture content of the salt, impurities, alkalinity or acidity, heat, light and humidity [29]. In the present study except for two mothers who added salt to food after cooking, the rest cooked the salt with food. Most stored the salt in containers likely to contain moisture, which could contribute to iodine loss. Only five women purchased salt from retail shops; the remainder (97\%) purchased salt from the open market. From our observation, salt sold in the open market is highly exposed to impurities, warm temperature and humidity.

\section{Knowledge related to iodized salt}

Due to the launch of the salt iodization program in Ethiopia, it may have been assumed that the general population understood the importance of iodine and that all salt in the market was iodized. However, $94 \%$ of the participants in our study reported they did not use iodized salt and $88 \%$ did not know the benefits of iodized salt. Of the relatively few mothers who reported knowing the benefits of iodized salt, all but one said it prevents goiter but none mentioned cognitive effects. The women suggested causes of goiter to be drinking dirty water, drinking tap water, or drinking rainwater, but only five percent said lack of iodine or lack of iodized salt. Although prevalence of goiter was high and visible in the community, knowledge of causes and of prevention of iodine deficiency disorders (IDDs) was minimal.

The fact that the majority of the mothers said they did not use iodized salt does not indicate the salt was not iodized, but rather that they did not know the difference between iodized and non-iodized salt. From our survey the iodized salt to the merchant was packed in $50 \mathrm{~kg}$ bags. Rural people, however. purchased minute amounts of salt. Therefore, there was no way for even the ones who could read to know the information labeled on the $50 \mathrm{~kg}$ bags. For effective transfer of information about iodine content and minimizing the loss as a result of poor storage conditions, packaging of iodized salt in smaller amounts would be worthwhile.

\section{CONCLUSION}

In conclusion, by far the most important source of iodine for this population should be iodized salt; however, the salt contained minimal but variable amounts of iodine. Low concentration of iodine in salt may be further compounded by storage, handling and cooking techniques. Until large-scale machinery based salt iodization and effective monitoring strategies are fully established, it is difficult to sustain a good quality salt 


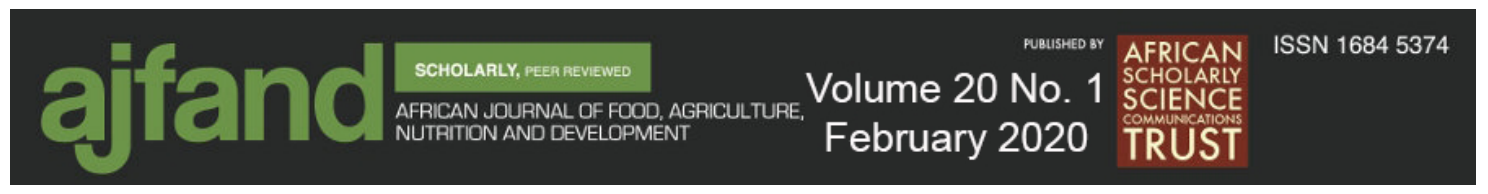

iodization program. Moreover, mechanisms should be devised to control the infiltration of non-iodized salt to the local market. In order to encourage the community to say 'No!' for non-iodized salt, it is indispensable to create awareness of causes, consequences and prevention of IDDs.

\section{Acknowledgements}

We thank the study participants and data collectors. Funders: This study was funded by the Nestlé Foundation and by the USDA Multistate Project, W-3002.

\section{Authors' Contributions}

Both authors have contributed to design, analysis and writing of this manuscript.

\section{Conflict of interests}

The authors declare no potential competing interests with respect to financial, authorship, or publication of this article. 


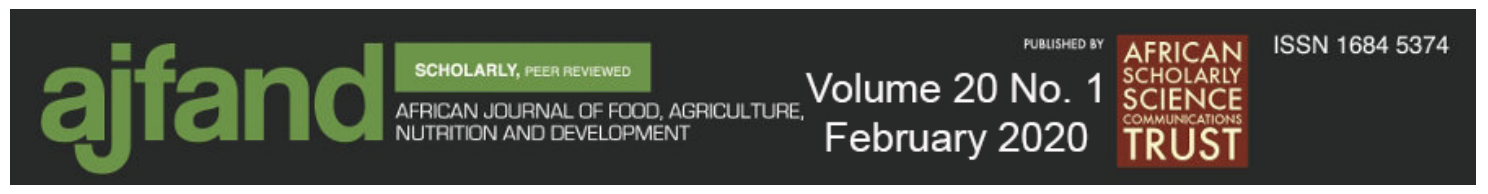

Table 1: Socio-demographic characteristics of study participants

\begin{tabular}{|c|c|c|}
\hline & Mean (SD) & Frequency $(\%)$ \\
\hline \multicolumn{3}{|l|}{ Mothers $(n=193)$} \\
\hline Mothers age (years) & $25.6(8.1)$ & \\
\hline Household size & $5.7(2.1)$ & \\
\hline Number of children & $3.2(1.8)$ & \\
\hline \multicolumn{3}{|l|}{ Mothers education (\%) } \\
\hline - No formal education & & $87(45)$ \\
\hline - Some education & & $106(55)$ \\
\hline \multicolumn{3}{|l|}{ Children $(n=76)$} \\
\hline Children's age (years) & $9.6(4.4)$ & \\
\hline \multicolumn{3}{|l|}{ Children's gender $(\%)$} \\
\hline - Male & & $46(60)$ \\
\hline - Female & & $30(40)$ \\
\hline
\end{tabular}




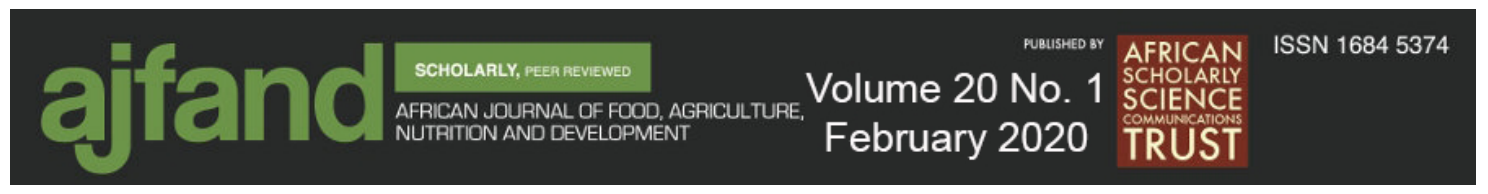

Table 2: Urinary iodine concentration of mothers and children and salt iodine concentration from Sidama zone, southern Ethiopia

\begin{tabular}{|c|c|c|}
\hline & Median (IQR) & Frequency $(\%)$ \\
\hline Maternal UIC $(\mu \mathrm{g} / \mathrm{L})$ & $143(84,202)$ & \\
\hline \multicolumn{3}{|l|}{ Maternal goiter } \\
\hline - No goiter & & $46(24)$ \\
\hline - Palpable goiter & & $50(26)$ \\
\hline - Visible goiter & & $97(50)$ \\
\hline Children's UIC $(\mu \mathrm{g} / \mathrm{L})$ & $187(102,278)$ & \\
\hline \multicolumn{3}{|l|}{ Children's goiter } \\
\hline - No goiter & & $16(21)$ \\
\hline - Palpable goiter & & $47(62)$ \\
\hline - Visible goiter & & $13(17)$ \\
\hline Household SIC (ppm) & $8.1(4.3,13.4)$ & \\
\hline$-\quad<5 \mathrm{ppm}$ & & $55(28.6)$ \\
\hline$-\quad 5-9.9 \mathrm{ppm}$ & & $61(31.8)$ \\
\hline$-\quad 10-15$ ppm & & $35(18.2)$ \\
\hline$-\quad>15 \mathrm{ppm}$ & & $41(21.4)$ \\
\hline - $\quad$ SIC range & 0 to $42 \mathrm{ppm}$ & \\
\hline
\end{tabular}




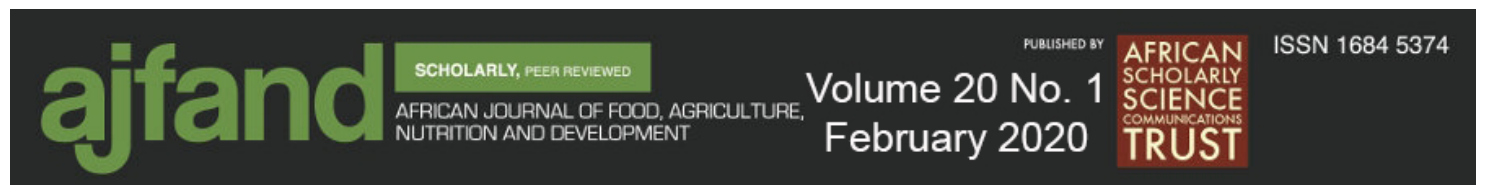

Table 3: Comparisons in maternal and child UIC by level of goiter, age and child sex; and association between children age and sex with goiter

\begin{tabular}{|c|c|c|c|c|c|}
\hline & $\begin{array}{l}\text { UIC } \\
(\mu \mathrm{g} / \mathrm{L}) \\
\text { Mean (SD) }\end{array}$ & $\mathrm{p}$ value & $\begin{array}{l}\text { Child } \\
\text { goiter }(\%)\end{array}$ & $\begin{array}{l}\text { Chi- } \\
\text { square test }\end{array}$ & $\mathrm{p}$ value \\
\hline Maternal goiter & & 0.167 & & & \\
\hline - No goiter & 189 (139) & & & & \\
\hline - Palpable goiter & $147(77)$ & & & & \\
\hline - Visible goiter & $158(115)$ & & & & \\
\hline Maternal age (years) & & 0.007 & & & \\
\hline$-\quad 17-20$ & $134(75)$ & & & & \\
\hline - $\quad 21-24$ & $154(102)$ & & & & \\
\hline$-\quad 25-28$ & $164(125)$ & & & & \\
\hline$-\quad \geq 29$ & $213(143)$ & & & & \\
\hline Child goiter & & 0.348 & & & \\
\hline - No goiter & $182(102)$ & & & & \\
\hline - Palpable goiter & $226(166)$ & & & & \\
\hline - Visible goiter & $278(216)$ & & & & \\
\hline Child age (years) & & 0.166 & & 13.3 & 0.01 \\
\hline$-5-8$ & $238(166)$ & & $26(34.2)$ & & \\
\hline$-9-12$ & $256(183)$ & & $16(21.0)$ & & \\
\hline$-\quad \geq 13$ & $162(116)$ & & $18(23.7)$ & & \\
\hline Child sex & & 0.403 & & 3.8 & 0.15 \\
\hline - Male & $210(163)$ & & $36(50)$ & & \\
\hline - Female & $243(160)$ & & $20(29)$ & & \\
\hline
\end{tabular}

Maternal goiter, maternal age and children goiter were analyzed by ANOVA and children age and sex were analyzed by Chi-square test 


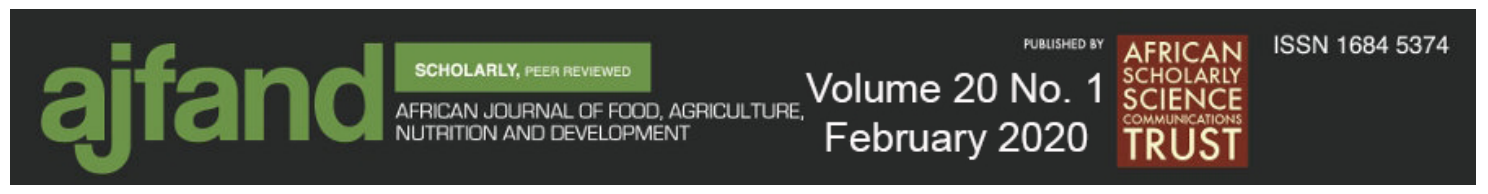

Table 4: Knowledge, attitudes and practices concerning household salt and goiter of women from Sidama zone, southern Ethiopia

\begin{tabular}{lll}
\hline Questions to the women & Frequency & Percent \\
\hline What kind of salt do you use? & & \\
- Rock salt & 192 & 99.5 \\
- Packed iodized salt & 1 & 0.5
\end{tabular}

Do you use iodized salt?

- Yes

- No

181

93.8

Do you know the benefits of iodized salt?

- Yes

- No

169

87.6

What is the benefit of iodized salt? $(n=24)$

- Prevents goiter

- Makes one strong

Do you know the causes of goiter?

- Yes

- No

What are the causes of goiter? $(\mathrm{n}=39)$

- Drinking dirty water

- Lack of iodine in salt

- Drinking tap water

10.3

- Drinking rain water

10.3

- Lack of food

5.1

- Lack of salt

- Lack of iodine

- Drinking untreated water

- Drinking river water

2.6

- Hereditary

2.6 


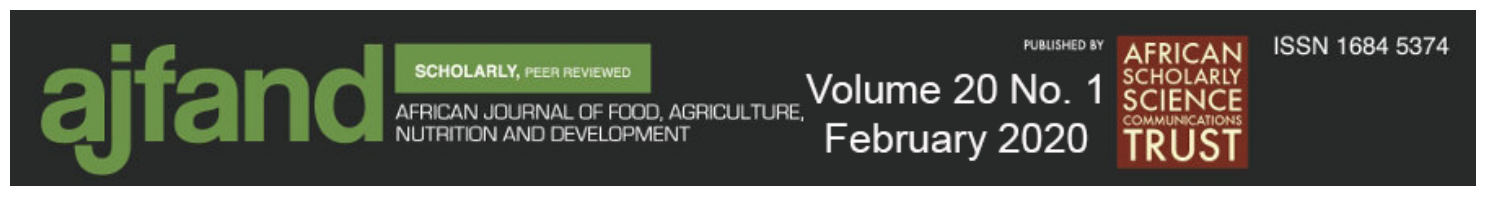

Table 5: Utilization and handling of salt by women from Sidama zone, southern Ethiopia

\begin{tabular}{lll}
\hline Questions to the women & Frequency & Percent \\
\hline $\begin{array}{l}\text { When do you add salt to food when } \\
\text { cooking? }\end{array}$ & 73 & \\
$\quad$ - Cook together & 120 & 37.8 \\
$\quad$ - At the end & & 62.2 \\
How much salt (tsp) do you add to each & & \\
food that you cook? & 130 & 67.4 \\
- $\quad$ One & 59 & 30.6 \\
- Two & 4 & 2 \\
- Three & & 10.9 \\
How do you store your salt? & 21 & 68.9 \\
- In a tight bottle & 133 & 19.7 \\
- In a water bottle & 38 & 0.5 \\
- In a plastic bag & 1 & \\
- Cover with paper & & \\
\hline
\end{tabular}




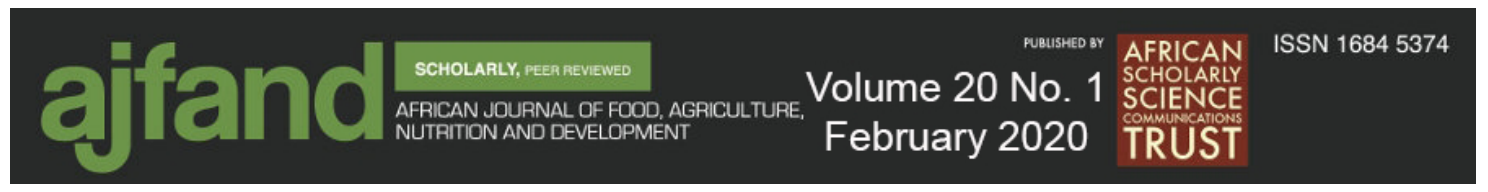

\section{REFERENCES}

1. de Benoist B, McLean E, Andersson M and L Rogers Iodine deficiency in 2007: global progress since 2003. Food. Nutr. Bull. 2008; 29:195-202.

2. Chan S and MD Kilby Thyroid hormone and central nervous system development. J. Endocrinol. 2000; 165:1-8.

3. Zimmermann MB Iodine deficiency. Endocr. Rev. 2009; 30:376-408.

4. Hetzel BS Iodine deficiency disorders (IDD) and their irradication. Lancet 1983; 2:1126-1129.

5. Pearce EN, Andersson $M$ and MB Zimmermann Global iodine nutrition: Where do we stand in 2013? Thyroid 2013; 23:523-528.

6. Abuye $\mathbf{C}$ and $\mathbf{Y}$ Berhane The goiter rate, its association with reproductive failure, and the knowledge of iodine deficiency disorders (IDD) among women in Ethiopia: Cross-section community based study. BMC. Public Health 2007; 7:316.

7. Abuye C, Berhane Y, Akalu G, Getahun Z and T Ersumo Prevalence of goiter in children 6 to 12 years of age in Ethiopia. Food. Nutr. Bull. 2007; 28:391-397.

8. Koutras DA, Matovinovic $\mathbf{J}$ and $\mathbf{R}$ Vought The ecology of iodine. In. JB Stanbury aBSH (Ed). Endemic Goiter and endemic cretinism. pp. 185-195. New York: John Wiley publ; 1980:185-195.

9. Horton $\mathbf{S}$ and A Miloff Iodine status and availability of iodized salt: An acrosscountry analysis. Food. Nutr. Bull. 2010; 31:214-220.

10. Vejbjerg P, Knudsen N, Perrild H, Carle A, Laurberg P, Pedersen IB, Rasmussen LB, Ovesen $\mathbf{L}$ and $\mathbf{T}$ Jorgensen Effect of a mandatory iodization program on thyroid gland volume based on individuals' age, gender, and preceding severity of dietary iodine deficiency: a prospective, population-based study. $J$. Clin. Endocrinol. Metab. 2007; 92:1397-1401.

11. Assey VD, Peterson S, Kimboka S, Ngemera D, Mgoba C, Ruhiye DM, Ndossi GD, Greiner $\mathbf{T}$ and $\mathbf{T}$ Tylleskar Tanzania national survey on iodine deficiency: impact after twelve years of salt iodation. BMC. Public Health 2009; 9:319.

12. Ethiopian Public Health Institute: National salt iodization coverage towards prevention of iodine deficiency disorders in Ethiopia. Addis Ababa, Ethiopia, 2014.

13. Bogale A, Abebe Y, Stoecker BJ, Abuye C, Ketema K and KM Hambidge Iodine status and cognitive function of women and their five year-old children in rural Sidama, southern Ethiopia. East. Afr. J. Public Health 2009; 6:296-299. 


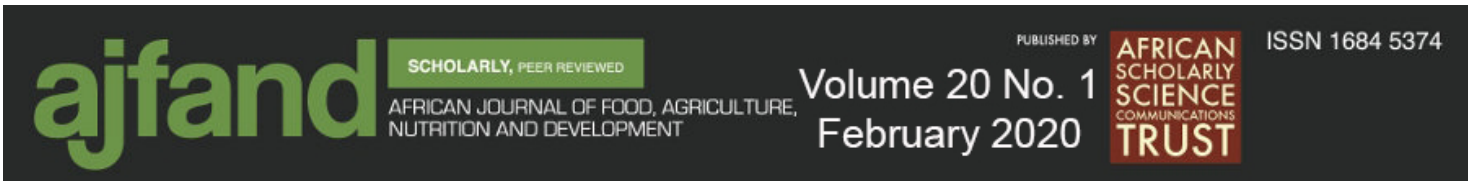

14. Ersino G, Tadele H, Bogale A, Abuye C and BJ Stoecker Clinical assessment of goiter and low urinary iodine concentration depict presence of severe iodine deficiency in pregnant Ethiopian women: a cross-sectional study in rural Sidama, southern Ethiopia. Ethiop. Med. J. 2013; 51:133-141.

15. Gebreegziabher T, Teyike N, Mulugeta A, Abebe Y, Hambidge KM and BJ Stoecker Lack of dietary sources of iodine and the prevalence of iodine deficiency in rural women from Sidama zone, southern Ethiopia. Afr. J. Food. Agric. Nutr. Dev. 2013; 13:8401-8414.

16. Abebe Y, Bogale A, Hambidge KM, Stoecker BJ, Bailey K and RS Gibson Phytate, zinc, iron and calcium content of selected raw and prepared foods consumed in rural Sidama, southern Ethiopia, and implications for bioavailability. J. Food. Comp. Anal. 2007; 20:161-168.

17. WHO/UNICEF/ICCIDD. Assessment of iodine deficiency disorders and monitoring their elimination. a guide for program managers. Third edition. World Health Organization, Geneva, 2007.

18. Carvalho AC, Machado A, Embalo AR and AA Bordalo Endemic goiter and iodine deficiency status among Guinea-Bissau school-age children. Eur. J. Clin. Nutr. 2018; 72:1576-1582.

19. Liang Z, Xu C and YJ Luo Association of iodized salt with goiter prevalence in Chinese populations: a continuity analysis over time. Mil. Med. Res. 2017; 4:8.

20. Farebrother J, Zimmermann MB, Abdallah F, Assey V, Fingerhut R, Gichohi-Wainaina WN, Hussein I, Makokha A, Sagno K and J Untoro Effect of excess iodine intake from iodized salt and/or groundwater iodine on thyroid function in nonpregnant and pregnant women, infants, and children: A multicenter study in east Africa. Thyroid 2018; 28:1198-1210.

21. Ren Q, Fan J, Zhang Z, Zheng $\mathbf{X}$ and RG DeLong An environmental approach to correcting iodine deficiency: Supplementing iodine in soil by iodination of irrigation water in remote areas. J. Trace Elem. Med. Biol. 2008; 22:1-8.

22. Abebe $\mathbf{Z}$, Gebeye $\mathbf{E}$ and $\mathbf{A}$ Tariku Poor dietary diversity, wealth status and use of un-iodized salt are associated with goiter among school children: a crosssectional study in Ethiopia. BMC Public Health 2017; 17:44.

23. Hailu S, Wubshet M, Woldie H and A Tariku Iodine deficiency and associated factors among school children: a cross-sectional study in Ethiopia. Arch. Public Health 2016; 74:46.

24. Muktar M, Roba KT, Mengistie B and B Gebremichael Goiter and its associated factors among primary school children aged 6-12 years in Anchar district, Eastern Ethiopia. PLoS ONE 2019; 14:1-12. 


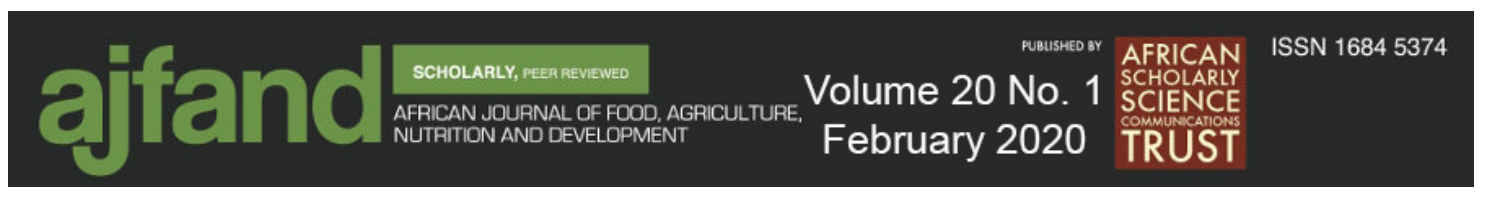

25. Abbag FI, Abu-Eshy SA, Mahfouz AA, Al-Fifi SA, El-Wadie H, Abdallah SM, Musa MG, Devansan CS and A Patel Iodine-deficiency disorders in the Aseer region, south-western Saudi Arabia: 20 years after the national survey and universal salt iodization. Public Health Nutr 2015;18:2523-9.

26. Laillou A, Mam B, Oeurn $\mathbf{S}$ and $\mathbf{C}$ Chea Iodized salt in Cambodia: trends from 2008 to 2014. Nutrients 2015; 7:4189-4198.

27. Zimmermann MB Assessing iodine status and monitoring progress of iodized salt programs. J. Nurtr. 2004; 134:1673 - 1677.

28. Shawel D, Hagos S, Lachat CK, Kimanya ME and $\mathbf{P}$ Kolsteren Postproduction losses in iodine concentration of salt hamper the control of iodine deficiency disorders: A case study in Northern Ethiopia. J. Health. Popul. Nutr. 2010; 28:238-244.

29. Kelly FC Studies on the stability of iodine compounds in iodized salt. Bull. World. Health. Organ. 1953; 9:217-230. 